\title{
Habitual joint cracking and radiological damage
}

A 25 year old Malaysian man who habitually elicited cracking sounds from many of his joints was investigated during a study of joint cracking. He had no symptoms or obvious abnormalities of his joints, but a radiograph of his right hand showed ligamentous ossification on the ulnar side of his third metacarpophalangeal joint and chondrocalcinosis in the first and fourth metacarpophalangeal joints (figure). There was no evidence of osteoarthrosis.

Distraction of the articular surfaces during finger pulling lowers the pressure of the synovial fluid. When the vapour pressure is reached the fluid evaporates, giving a cracking sound and forming an intra-articular bubble. Previous studies have reached conflicting conclusions about the radiological changes found in habitual finger cracking, ${ }^{12}$ but we suggest that excessive joint cracking may have caused the changes seen in this subject, who had no signs of any other underlying disease. - P WATSON, A HAMILTON, R MOLLAN, department of orthopaedic surgery, Musgrave Park Hospital, Belfast BT9 $7 \mathcal{F B .}$

1 Unsworth A, Dowson D, Wright V. Cracking joints. A bioengineering study of cavitation in the metacarpophalangeal joint. Ann Rheum Dis 1971;30:348-58. (M Ziff, discussion.)

2 Swezey RL, Swezey SE. The consequences of habitual knuckle cracking. West $\mathcal{I}$ Med 1975 122:377-9.

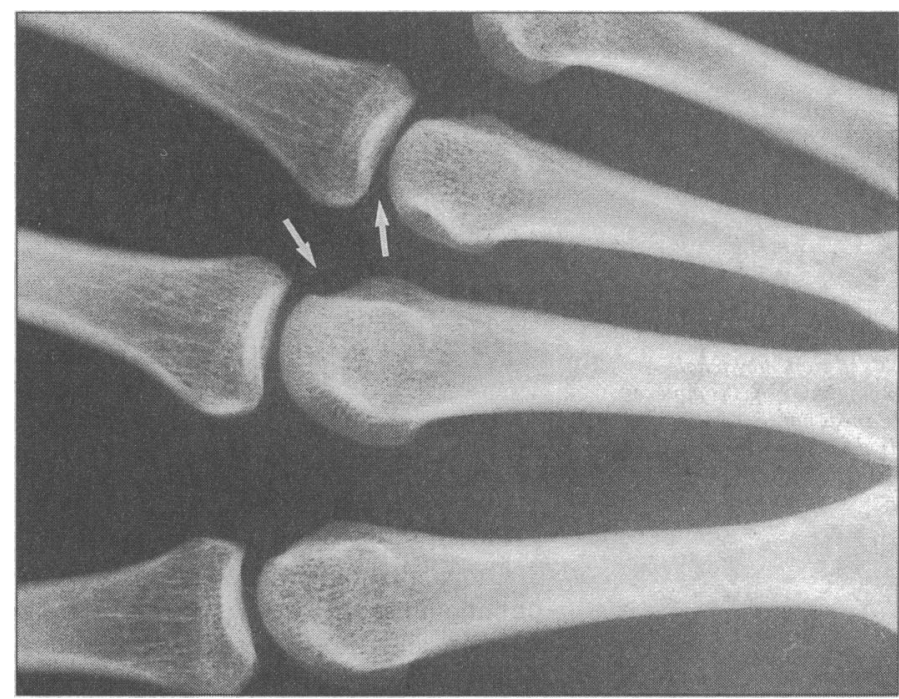

\section{Successful treatment of subdural haematoma during anticoagulant treatment}

A 66 year old woman taking warfarin as anticoagulation after receiving a Starr Edwards mitral valve prosthesis had developed disturbance of her memory and headaches over six weeks. Hospital admission was precipitated by increasing unsteadiness of gait, confusion, and somnolence over the preceding three days. She was drowsy and disoriented with a temperature of $37 \cdot 5^{\circ} \mathrm{C}$. An unenhanced computed tomogram (figure (left)) showed an extensive right frontoparietal subdural haematoma of mixed low and high density, with midline displacement and compression of the right lateral ventricle. Because of the risk of mitral valve thrombosis if warfarin was withdrawn and the risk of surgical evacuation with anticoagulation she was managed with dexamethasone and bed rest. Despite anticoagulation with warfarin being maintained there was progressive improvement in her mental state, and a repeat computed tomogram four months later showed complete resolution of the subdural haematoma (figure (right)).

Although there is no previous report of spontaneous resolution of a subdural haematoma while anticoagulation is maintained, we suggest that conservative treatment is possible in some closely monitored patients. - T J ANDERSON, I M DONALDSON, departments of neurology and medicine, Christchurch Hospital, Christchurch, New Zealand
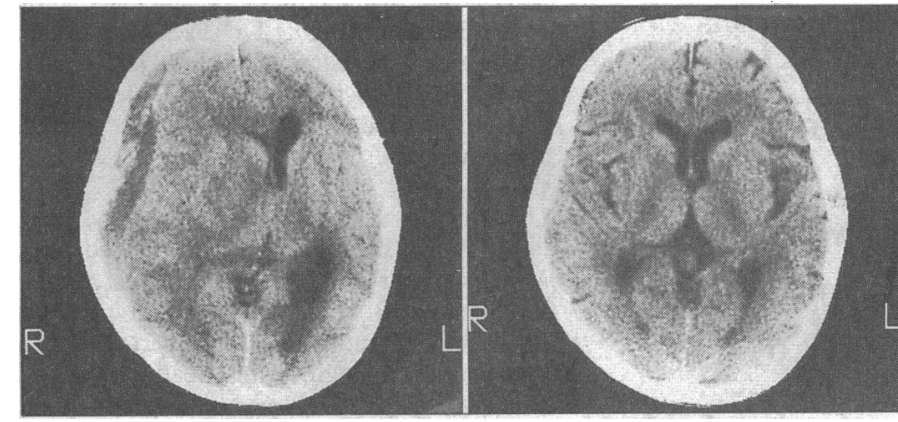
Newport, Gwent 